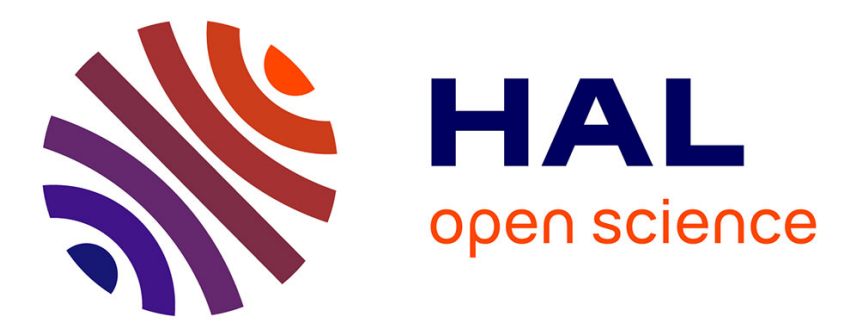

\title{
Earth blocks stabilized by cow-dung
}

Younoussa Millogo, Jean-Emmanuel Aubert, Ahmed Douani Séré, Antonin

Fabbri, Jean-Claude Morel

\section{To cite this version:}

Younoussa Millogo, Jean-Emmanuel Aubert, Ahmed Douani Séré, Antonin Fabbri, Jean-Claude Morel. Earth blocks stabilized by cow-dung. Materials and structures, 2016, 49 (11), pp.4583 4594. 10.1617/s11527-016-0808-6 . hal-01876848

\section{HAL Id: hal-01876848 \\ https://hal.science/hal-01876848}

Submitted on 18 Sep 2018

HAL is a multi-disciplinary open access archive for the deposit and dissemination of scientific research documents, whether they are published or not. The documents may come from teaching and research institutions in France or abroad, or from public or private research centers.
L'archive ouverte pluridisciplinaire HAL, est destinée au dépôt et à la diffusion de documents scientifiques de niveau recherche, publiés ou non, émanant des établissements d'enseignement et de recherche français ou étrangers, des laboratoires publics ou privés. 


\title{
Earth blocks stabilized by cow-dung
}

\author{
Younoussa Millogo ${ }^{\mathrm{a}, \mathrm{b}}$, Jean-Emmanuel Aubert ${ }^{\mathrm{c}}$, Ahmed Douani Séré ${ }^{\mathrm{a}}$, Antonin Fabbri ${ }^{\mathrm{d}}$, \\ Jean-Claude Morel $^{\mathrm{e}}$ \\ ${ }^{a}$ Unité de Formation et de Recherche en Sciences et Techniques (UFR/ST), Université Polytechnique \\ de Bobo-Dioulasso, 01 BP 1091 Bobo 01, Burkina Faso. \\ ${ }^{b}$ Laboratoire de Chimie Moléculaire et des Matériaux (LCMM), UFR/Sciences Exactes et Appliquées, \\ Université de Ouagadougou, 03 B.P. 7021 Ouagadougou 03, Burkina Faso \\ ${ }^{c}$ Université de Toulouse; UPS, INSA; LMDC (Laboratoire Matériaux et Durabilité des Constructions), \\ 135 avenue de Rangueil, F-31 077 Toulouse cedex 4, France \\ ${ }^{d}$ Université de Lyon Laboratoire Génie Civil et Bâtiment, LTDS UMR 5513 CNRS, Ecole Nationale \\ des Travaux Publics de l'Etat, Rue Maurice Audin, 69518 Vaulx en Velin cedex, France \\ ${ }^{e}$ Centre for Low Impact Buildings, Faculty of Engineering, Environment and Computing, Coventry \\ University, CV1 5FB, United Kingdom
}

\begin{abstract}
In developing countries, most of the population cannot afford conventional building blocks made with the sand-cement mixture. In addition, these blocks do not provide thermal comfort and have a high embodied energy compared to vernacular materials. The main objective of this work was to produce low cost, resistant and durable (good resistance to water) blocks with a thermal behaviour enabling quality comfort indoor. For that purpose, the effects of cow-dung on microstructural changes in earth blocks (adobes) are investigated by means of X-ray diffraction, thermal gravimetric analyses, scanning electronic microscopy coupled with energy dispersive spectrometry, and video microscopy. The effects of these changes on the physical properties (water absorption and linear shrinkage) and mechanical properties (flexural and compressive strengths) of adobe blocks are evaluated. It is shown that cow-dung reacts with kaolinite and fine quartz to produce insoluble silicate amine, which glues the isolated soil particles together. Moreover, the significant presence of fibres in cow-dung prevents the propagation of cracks in the adobes and thus reinforces the material. The above phenomena make the adobe microstructure homogeneous with an apparent reduction of the porosity. The major effect of cow-dung additions is a significant improvement in the water resistance of adobe, which leads to the conclusion that adobes stabilized by cow-dung are suitable as building materials in wet climates.
\end{abstract}

Keywords: Adobe, cow-dung, insoluble silicate amine, lateritic clay, microstructure changes, physical and mechanical properties

*Corresponding author. Tel. 0033 (0)5 61556697 Fax: 0033 (0)5 615599 49;

e-mail: jean-emmanuel.aubert@univ-tlse3.fr 


\section{Introduction}

Cow-dung is abundant due to the large numbers of cows locally available in a large geographic area of the world. The main components of cow-dung are plant fibres (essentially composed of cellulose, hemicelluloses and lignin), amine organic compounds, and fragments of intestinal tissues. It contains 80 to $90 \mathrm{wt}$. \% of water. Its numerous properties are of interest in several domains. Its very exothermic combustion makes it an excellent fuel. For this reason, it is used in pottery kilns for the firing of cooking pots. It could be used in medicine to prevent inflammation and pains because of its antiseptic character. Generally, cow-dung is mainly used to fertilize agricultural soils because its high nitrogen content is important for the development of plants.

Like rammed earth or Compressed Earth Blocks, adobes are considered as green building materials because they have low embodied carbon compared to conventional materials such as concrete and fired clay bricks. For these reasons, in recent decades, new research has focused on earth as a construction material throughout the world. In the building industry in Africa, and especially in Burkina Faso, cow-dung is used in adobe structures as floor coating, for stabilizing adobe blocks and plasters, and is commonly used in outside coatings to protect houses against erosion during the rainy season. This empirical practice improves the water resistance and durability of adobes and plasters.

Abundant literature is available on the effects of straw debris, cement, lime and natural plant fibres on the physical and mechanical properties of adobes (Ghavami et al. 1999; Mesbah et al. 2004; Pacheco-Torgal and Jalali 2012; Morel JC et al. 2013; Millogo et al. 2014; Danso et al. 2015; Millogo et al. 2015) but very few papers deal with the effects of cow-dung on these properties (Ngowi 1997; Vilane 2010). Ngowi (1997) examined methods of improving earth construction in two major villages in Botswana where cow-dung was traditionally used as a stabilizer. The author compared cow-dung with other stabilizers: cement, lime and bitumen, regarding the water absorption and compressive strength. More than twenty years later, Vilane (2010) investigated the effect of molasses, cow-dung, sawdust and ordinary Portland cement (OPC) stabilizers on the compressive strength of adobe blocks. The results demonstrated that, with suitable soil, molasses, cow-dung and sawdust could be used as effective stabilizers but OPC stabilized blocks attained higher confined compressive strengths than all the other stabilizers. These two papers essentially focused on compressive strength and water absorption, paying little attention to the characterization of cow-dung. Moreover, the effects of cow-dung addition on the microstructure of adobe was not evaluated, in particular the mechanism of cow-dung binding with the clay matrix.

In developing countries, most of the population cannot afford conventional blocks made with the sand-cement mixture. In addition to their high intrinsic cost, these conventional blocks do not provide sufficient thermal comfort during the warmest periods, and populations need to spend a quite important amount of money to refresh their houses. The goal of this research was to propose an alternative approach, based on the valorisation of local materials, clay materials and organic wastes, which is better suited to the social and economic realities of these countries. The main objective was to produce low cost, resistant and durable (resistance to water) blocks with a thermal comfort.

The present work studies the effects of cow-dung additions on the microstructural transformations and the physical and mechanical properties of adobes made with a raw clay material from Burkina Faso. First, the physical (particle size distribution, Atterberg limits) and mineralogical (X-ray diffraction and thermal gravimetric analyses) characteristics of the raw materials (soil and cow-dung) were studied. Then, the properties of hardened adobes 
stabilized by cow-dung were measured, essentially by measuring their mechanical characteristics (linear shrinkage, flexural and compressive strength) and properties related to their durability (water absorption).

\section{Materials and experimental procedures}

\subsection{Raw materials and manufacture of adobes}

The soil used in this work for the manufacture of adobes was lateritic clay from the old Kamboinsin pit (in the Ouagadougou area). The dried cow-dung was collected from farms around Ouagadougou.

Raw lateritic clay material and the cow-dung were dried and crushed in agate mortar down to particle sizes lower than $0.4 \mathrm{~mm}$. Different amounts of dried cow-dung powder $(0,1,2$ and 3 wt.\%) were mixed with dried powder of raw material. In order to have the same workability, an amount of water, calculated from the relation: $\mathrm{w}(\%)=\left(\mathrm{w}_{\mathrm{L}}+\mathrm{w}_{\mathrm{P}}\right) / 2$ where $\mathrm{w}_{\mathrm{L}}$ and $\mathrm{w}_{\mathrm{P}}$ are respectively the liquid and plastic limits, was added to all the formulations. The device used for the manufacture of the pastes is presented in Fig.1. The pastes obtained were homogenized for $15 \mathrm{~min}$ and kept in plastic bags in a temperature controlled room $\left(20^{\circ} \mathrm{C}\right)$ for $72 \mathrm{~h}$ to allow the cow-dung to ferment. After this step, the pastes were manually pressed into prismatic moulds $\left(4 \times 4 \times 16 \mathrm{~cm}^{3}\right)$ and kept in situ for $24 \mathrm{~h}$ (cf. Fig. 2). The as-moulded adobes were stored for 21 days at room temperature. The relative humidity and the room temperature were respectively $60 \%$ and $30^{\circ} \mathrm{C}$. This curing protocol and time were chosen because they corresponded to those used traditionally in villages of Burkina Faso.

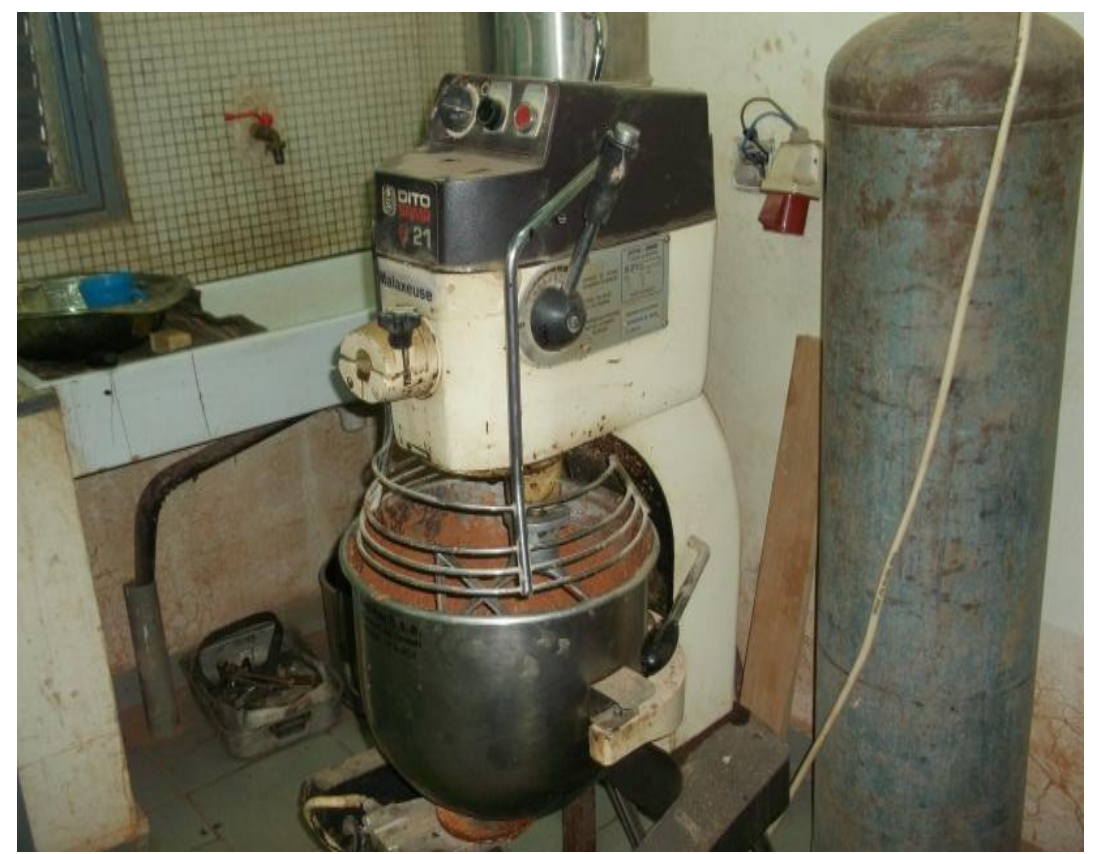

Fig.1: Picture of the device used for the preparation of the paste 


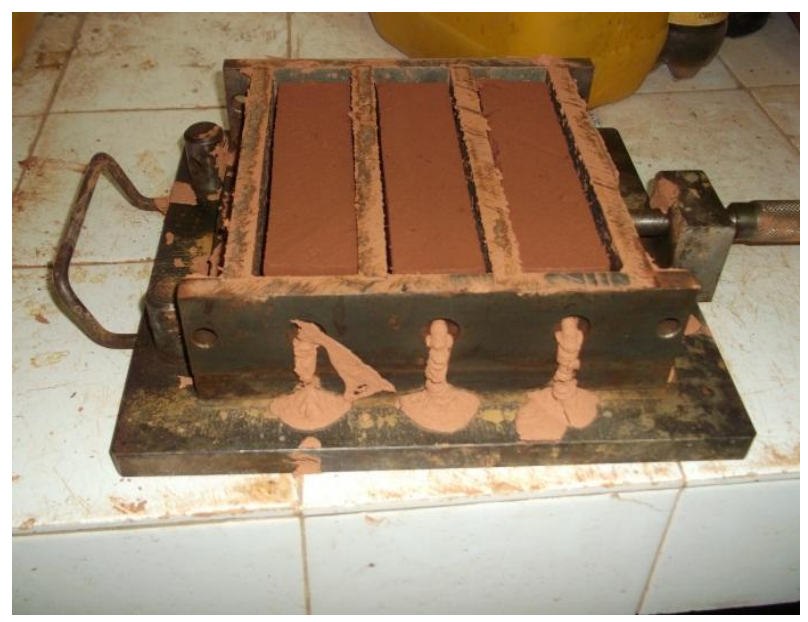

Fig.2: Picture of the paste within the prismatic moulds

\subsection{Experimental procedures}

The size distribution of the soil mixtures was analysed using two techniques: the coarser fraction $(>80 \mathrm{~mm})$ was analysed by wet sieving, and the finer fraction by means of pipette analysis according to standard NF P 94-057 (method based on the measurement of the sedimentation time of solid particles in suspension in a solution of water mixed with sodium hexametaphosphate as a deflocculating agent).

The geotechnical characteristics of the soils contained in the materials were determined by measuring the Atterberg limits and the methylene blue value.

The chemical composition of the raw materials was estimated on digested crushed samples of size $<80 \mu \mathrm{m}$ by Inductively Coupled Plasma - Atomic Emission Spectrometry (ICP-AES). The loss on ignition was evaluated by sample calcination up to $1000^{\circ} \mathrm{C}$.

X-ray diffraction and Thermal Gravimetric Analyses (TGA) were used to study the mineralogical composition of the raw materials. The X-ray diffraction apparatus used was a Siemens D5000 power X-ray Diffractometer equipped with a monochromator using a $\mathrm{K} \alpha(\lambda=$ $1.789 \AA$ ) cobalt anticathode. TGA were carried out on a crushed sample of cow-dung heated to $1000^{\circ} \mathrm{C}$ at a constant rate of $10^{\circ} \mathrm{C} / \mathrm{min}$ using a Netzsch SATA $449 \mathrm{~F} 3$ Jupiter apparatus.

A JEOL $6380 \mathrm{LV}$ equipped with a backscattered electron (BSE) detector was used for SEM observations on cow-dung powder and the cow-dung morphology study was completed using a Keyence VH-5911 area video microscope.

The flexural strength of adobes was determined at a loading rate of $50 \mathrm{~N} / \mathrm{s}$ using a R.M.UTesting equipment Bergamo on three specimens. Its operating mode is based on the wellknown 3-points bending test. The accuracy on the flexural strength measurement is $5 \%$. The compression stress loading rate was $2400 \mathrm{~N} / \mathrm{s}$ using a hydraulic press multitester type Controls with an accuracy of $3 \%$.

For each formulation, three samples were used to determine the flexural strength and the six half specimens obtained after the 3-point bending test were considered for the uniaxial compression test. Both flexural and compressive strength measurements were performed according to NF P14-306. In this standard, dedicated to cellular concrete, no system is used to reduce the confinement (Aubert et al. 2013; Aubert et al. 2015). The water absorption of adobes was evaluated according to the NF P13-305 standard on three specimens, as it is recommended. The linear shrinkage values were evaluated from the variation of length, measured using a calliper on three specimens. The samples before and after the flexural strength test are presented in figure 3. 


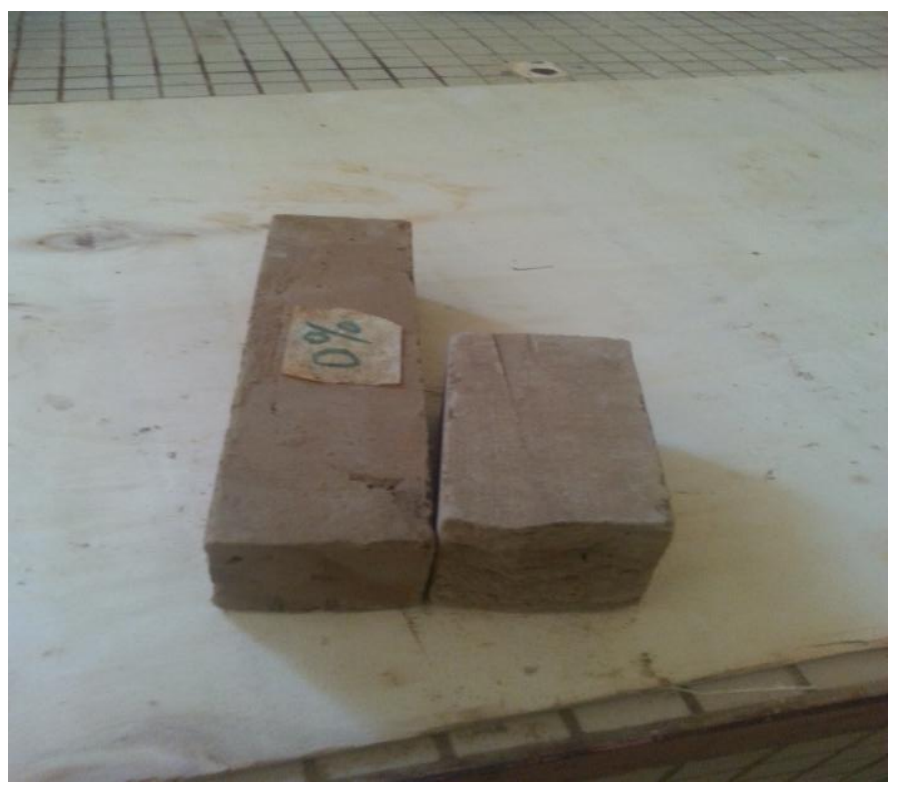

Fig.3: The samples before and after the flexural strength test

\section{Results and discussion}

\subsection{Characterization of raw materials}

The particle size distribution curve for the soil is presented in Fig. 4.

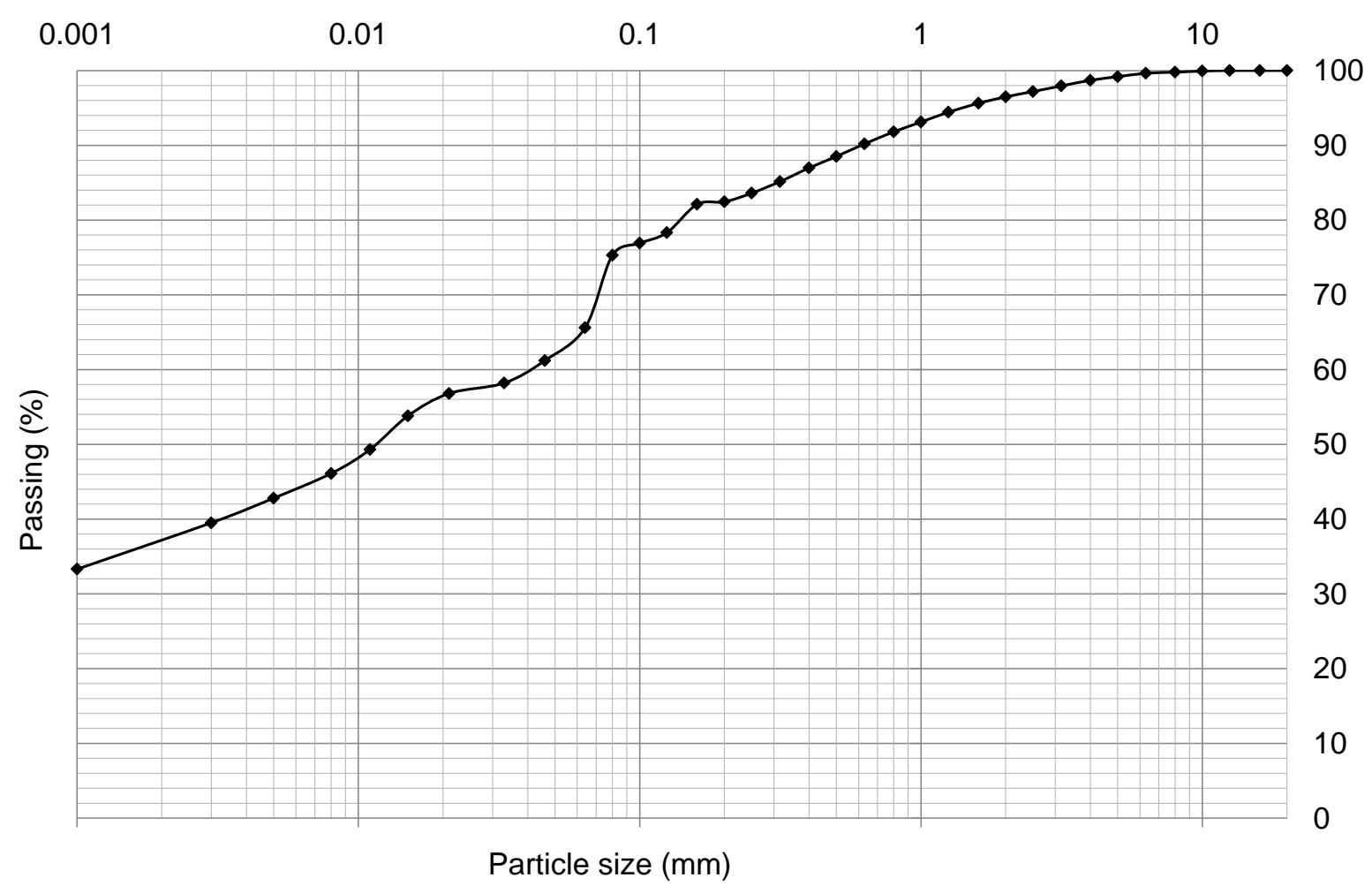

Fig. 4: Particle size distribution of the soil

A careful examination of this curve shows that the soil is made up of $43 \mathrm{wt} . \%$ sand, $17.5 \mathrm{wt} . \%$ silt and $36 \mathrm{wt} . \%$ clay, while the quantity of coarse particles is fairly low (3.5 skeleton wt.\%). Considering the above results, it could be concluded that the sample is rich in fine fractions and is therefore suitable for making adobe. The plasticity index $\left(\mathrm{I}_{\mathrm{p}}\right)$ of the material studied 
was $24 \%$, indicating a medium plastic sample according to the standard XP P94-011. The methylene blue value of the raw material was $1.57 \mathrm{~g} / 100 \mathrm{~g}$ and its clay activity was 4.9 , which is quite close to that of kaolinite. Considering these results, it could be deduced that the sample did not contain swelling clayey minerals because its methylene blue value was near to that of kaolinite.

The chemical composition of the soil is presented in Table 1.

Table 1: Chemical composition of the soil

\begin{tabular}{lllllllllllll}
\hline Oxides & $\mathrm{SiO}_{2}$ & $\mathrm{Al}_{2} \mathrm{O}_{3}$ & $\mathrm{Fe}_{2} \mathrm{O}_{3}$ & $\mathrm{MgO}$ & $\mathrm{CaO}$ & $\mathrm{P}_{2} \mathrm{O}_{5}$ & $\mathrm{MnO}$ & $\mathrm{Na}_{2} \mathrm{O}$ & $\mathrm{K}_{2} \mathrm{O}$ & $\mathrm{TiO}_{2}$ & $\mathrm{LOI}^{*}$ & Total \\
\hline Wt.\% & 49.88 & 25.95 & 9.69 & 0.17 & 0.05 & 0.04 & 0.05 & 0.03 & 0.39 & 1.12 & 11.78 & 99.15
\end{tabular}

* Loss on ignition at $1000^{\circ} \mathrm{C}$

The soil under study was mainly composed of silica, alumina and iron oxide. From the silica and alumina amounts, the loss on ignition and the methylene blue value of the sample, it could be concluded that this soil was rich in kaolinite with appreciable amounts of quartz and iron minerals.

The X-ray diffraction spectrum of the soil (Fig. 5) confirmed that it contained kaolinite $\left(\mathrm{Al}_{2}\left(\mathrm{Si}_{2} \mathrm{O}_{5}\right)(\mathrm{OH})_{4}\right)$, quartz $\left(\mathrm{SiO}_{2}\right)$ and goethite $(\mathrm{FeOOH})$.

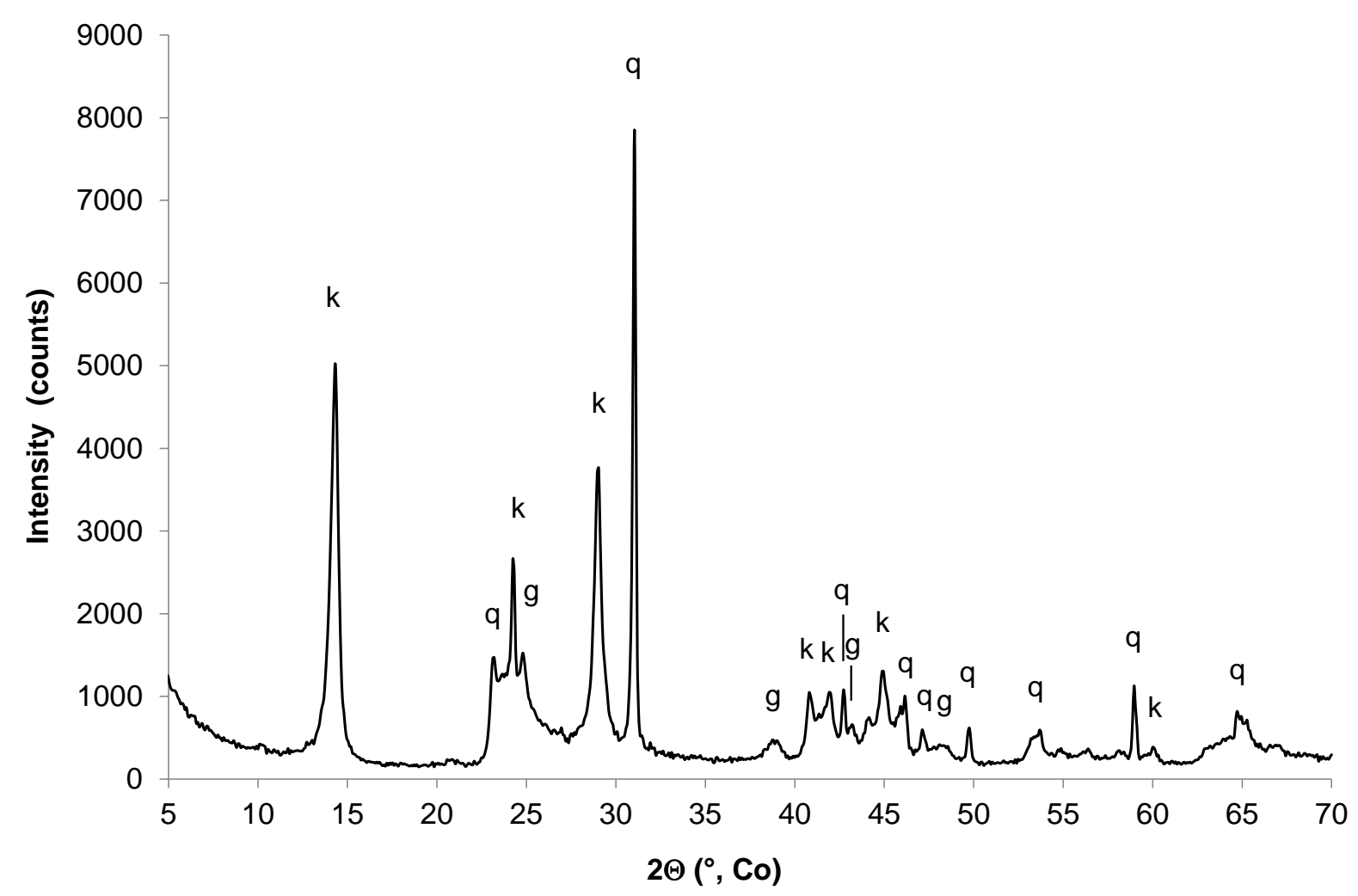

Caption: g: goethite $(\mathrm{FeO}(\mathrm{OH}))$, k: kaolinite $\left(\mathrm{Al}_{2}\left(\mathrm{Si}_{2} \mathrm{O}_{5}\right)(\mathrm{OH})_{4}\right)$, q: quartz $\left(\mathrm{SiO}_{2}\right)$

Fig. 5: X-ray diffraction pattern of the soil

The mineralogical composition of the soil was obtained by using the mineralogical composition by X-ray diffraction and the chemical composition of the sample. The sample studied in this paper contained $66 \mathrm{wt} . \%$ of kaolinite, $21 \mathrm{wt} . \%$ of quartz and $18 \mathrm{wt} . \%$ of goethite. 
The thermal gravimetric analyses presented in Fig.6 show the presence of four main peaks, around $130,216,297$ and $535^{\circ} \mathrm{C}$, corresponding to the loss of hygroscopic water, water strongly linked to the material, the dehydroxylation of goethite and the dehydroxylation of kaolinite respectively.

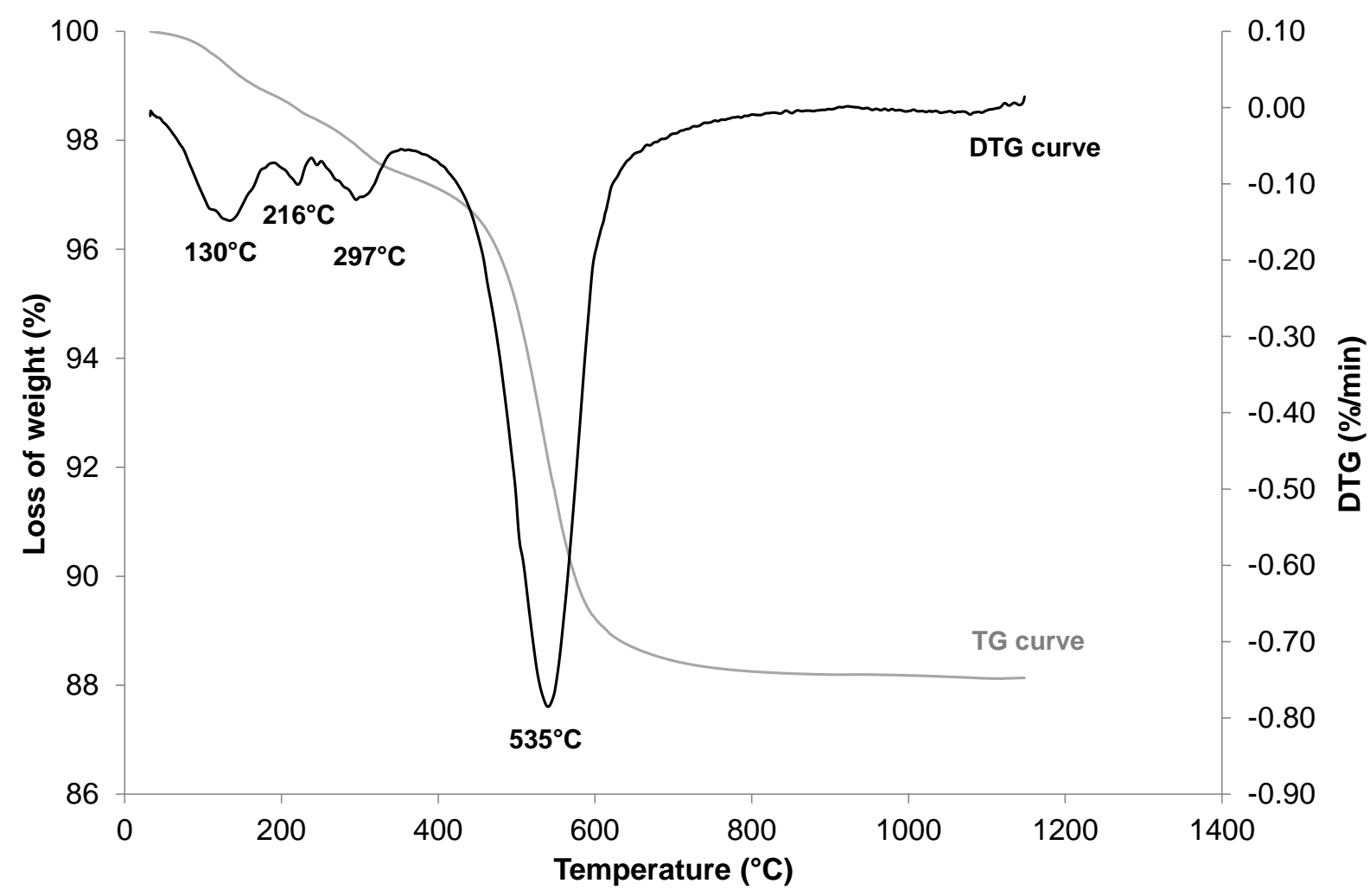

Fig. 6: Thermal gravimetric and differential thermal gravimetric analyses of the soil

Thermal gravimetric analyses of the cow-dung are presented in Fig. 7. 


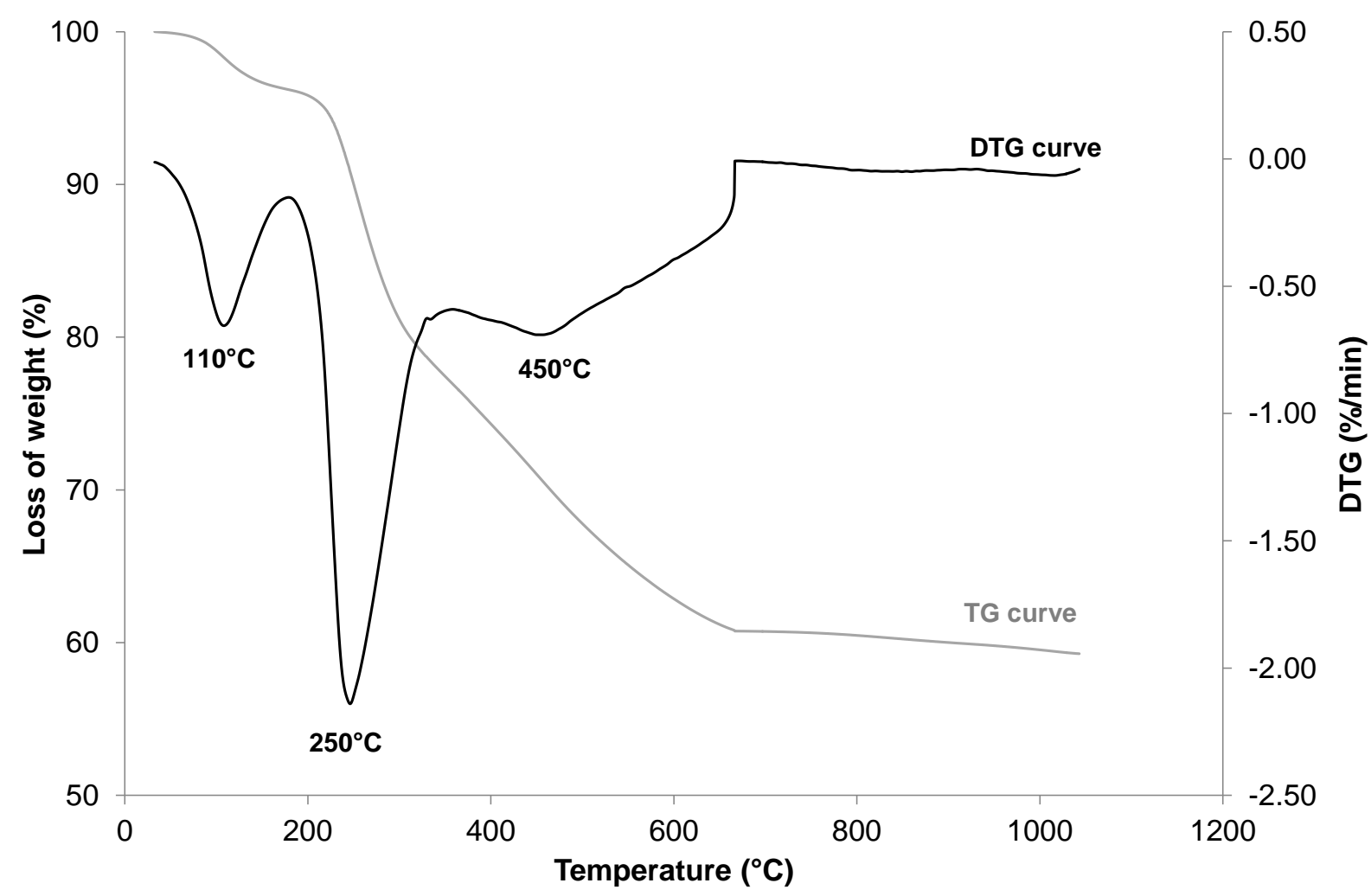

Fig. 7: Thermal gravimetric and differential thermal gravimetric analyses of cow-dung

The analysis of Figure 4 used the works of El-Shekeil et al. (2012) and Morān et al. (2008). The first mass loss step around $110^{\circ} \mathrm{C}$ is due to hygroscopic water. The appreciable mass loss around $250^{\circ} \mathrm{C}$ is linked to the decomposition of thermally unstable compounds such as nonstructural hemicelluloses and concerns the depolymerization of these hemicelluloses. This peak could also express the degradation of lignin. The large peak around $400-525^{\circ} \mathrm{C}$ is probably attributable to the structural hemicelluloses, lignin and cellulose, which are pyrolysed at this temperature. It could also be attributed to the dehydroxylation of clay minerals because of the nature of cow-dung, which could contain some particles of soil as contaminants.

The scanning electronic microscope (SEM) images paired with the energy dispersive spectrometry (EDS) of the cow-dung are presented in Fig. 8. 

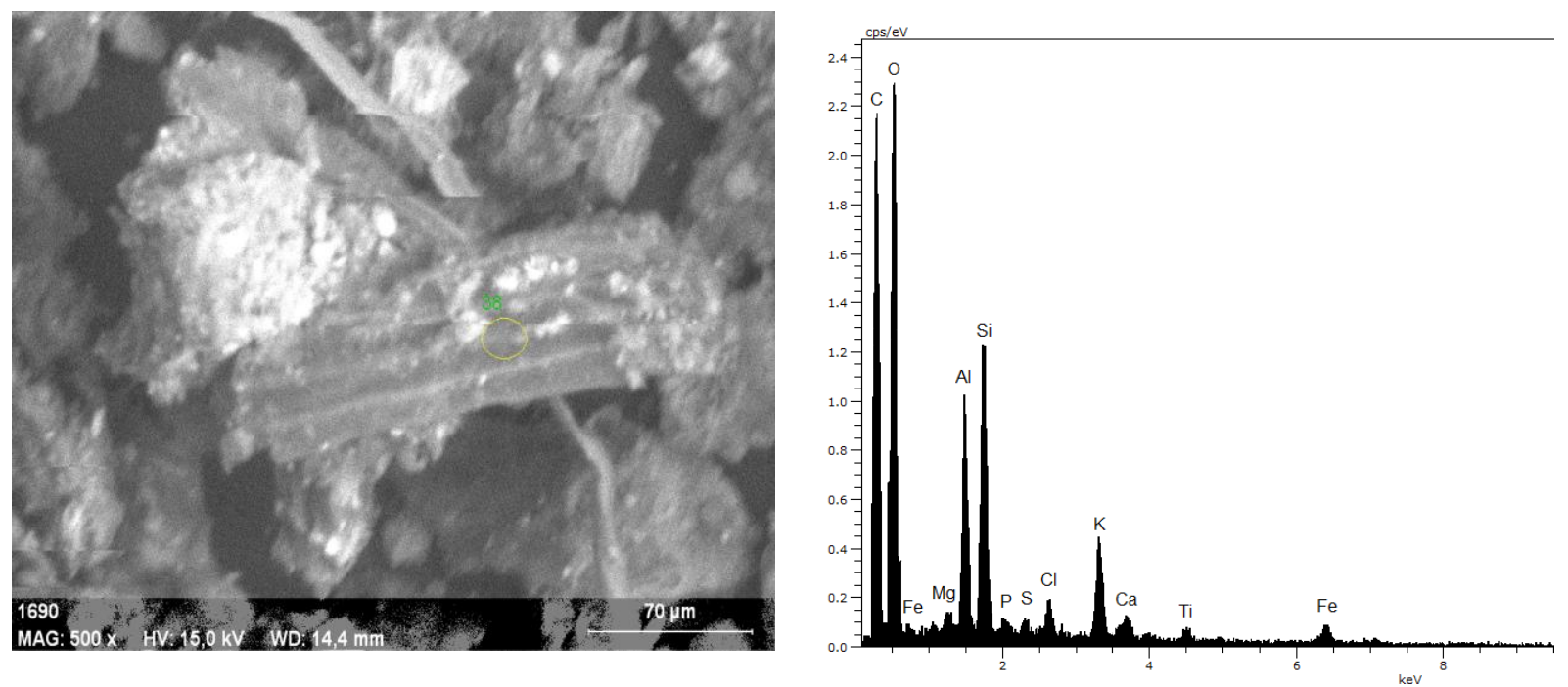

Fig. 8: Scanning electronic microscopy and EDS analyses of the cow-dung

The SEM micrograph of the cow-dung shows pieces of fibres that were in food eaten by the cows but were not digested. The EDS analyses of the cow-dung shows that it contained mainly silica, alumina, sulphur, phosphorous, calcium and potassium and iron compounds. The presence of silica and alumina confirms the presence of clay minerals as was predicted by the thermograms. According to the video microscopy image of cow-dung presented in Fig. 9, plant fibres are its major component and this could have a positive effect on the physical and mechanical characteristics of adobes amended with cow-dung because of the large amount of cellulose in the fibres. Moreover, this image shows that the natural plant fibres contained in cow-dung have a rough surface, which would improve the adherence between these fibres and the soil in adobes and thus their mechanical strength.

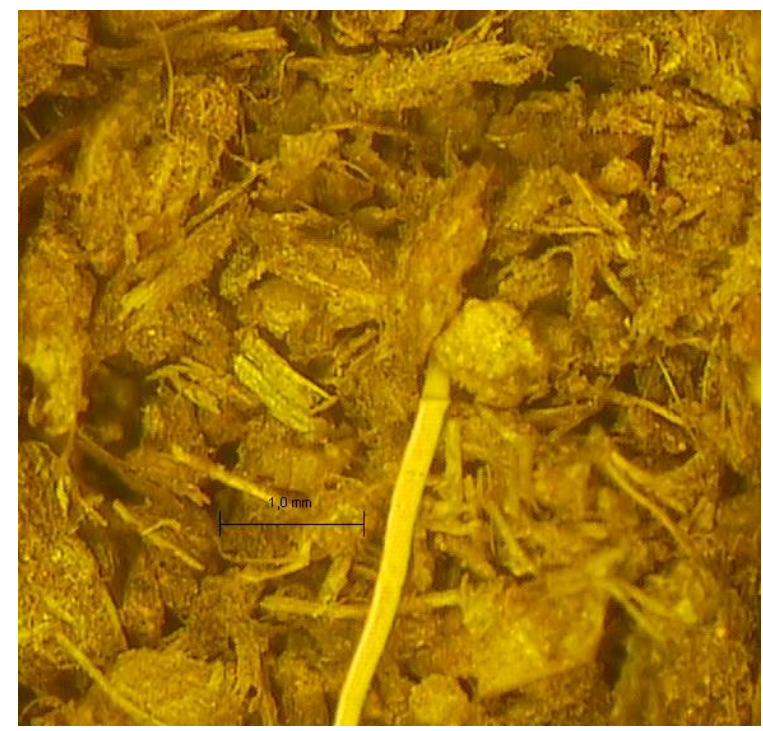

Fig. 9: Video microscopy image of cow-dung

\subsection{Reaction mechanism of cow-dung with soil particles}

To highlight how cow-dung reacts with the clay matrix, X-ray diffraction patterns were obtained for adobes amended with various cow-dung contents $(1,2$ or $3 \%)$ or without such additions. The XRD patterns of the 21-day-old materials are presented in Fig. 10. 


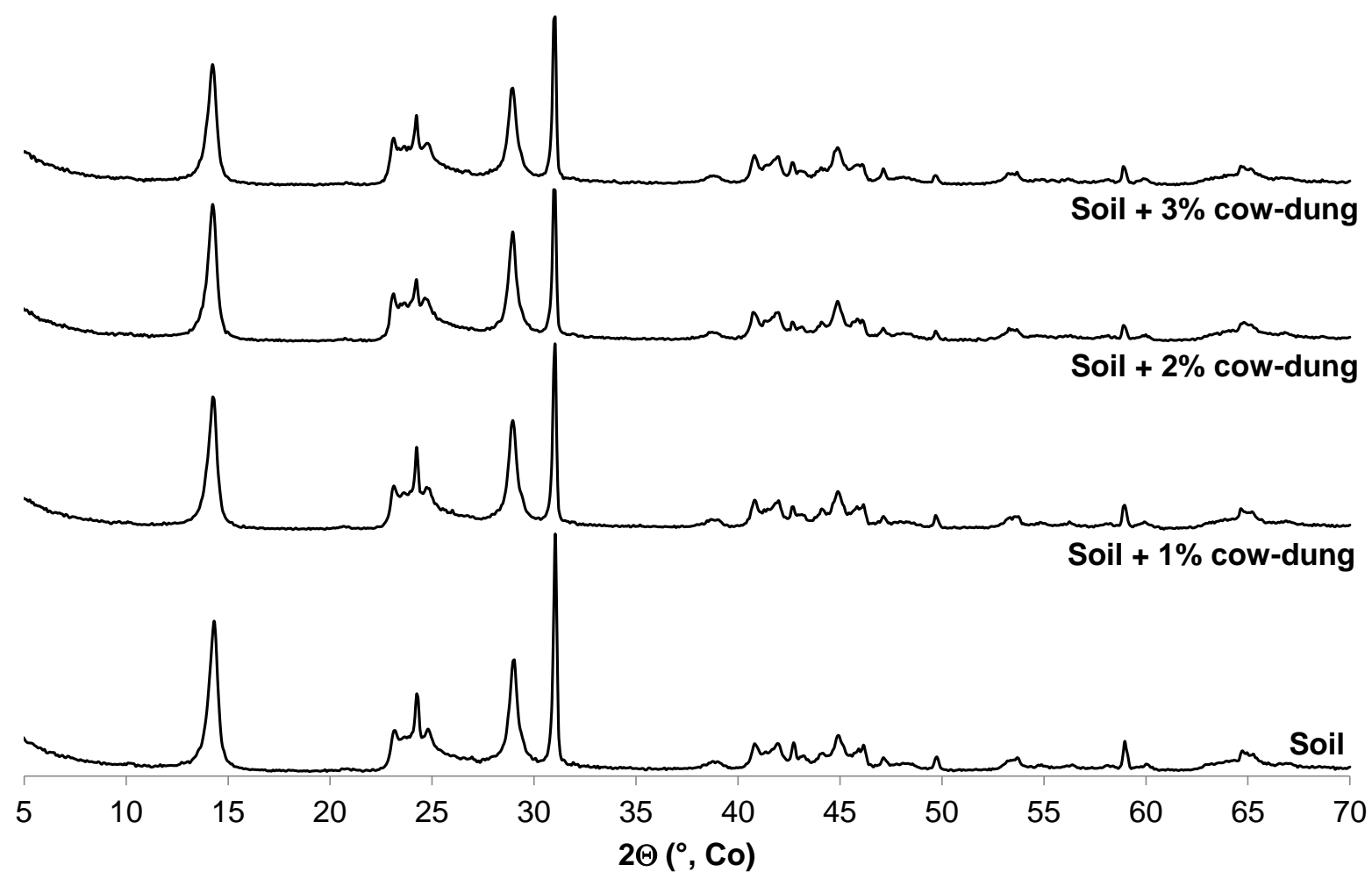

Fig. 10: X-ray diffraction patterns of adobes amended or not with cow-dung

The X-ray patterns of adobes mixed with cow-dung do not show evidence of the formation of new crystallized phases but the intensity of the prominent peak of kaolinite (basal peak) located at $14.25^{\circ}$ in two theta and the prominent peak of quartz located at $31.03^{\circ}$ in two theta decrease significantly with cow-dung additions. The decrease of these two peaks is reported in Fig. 11. 


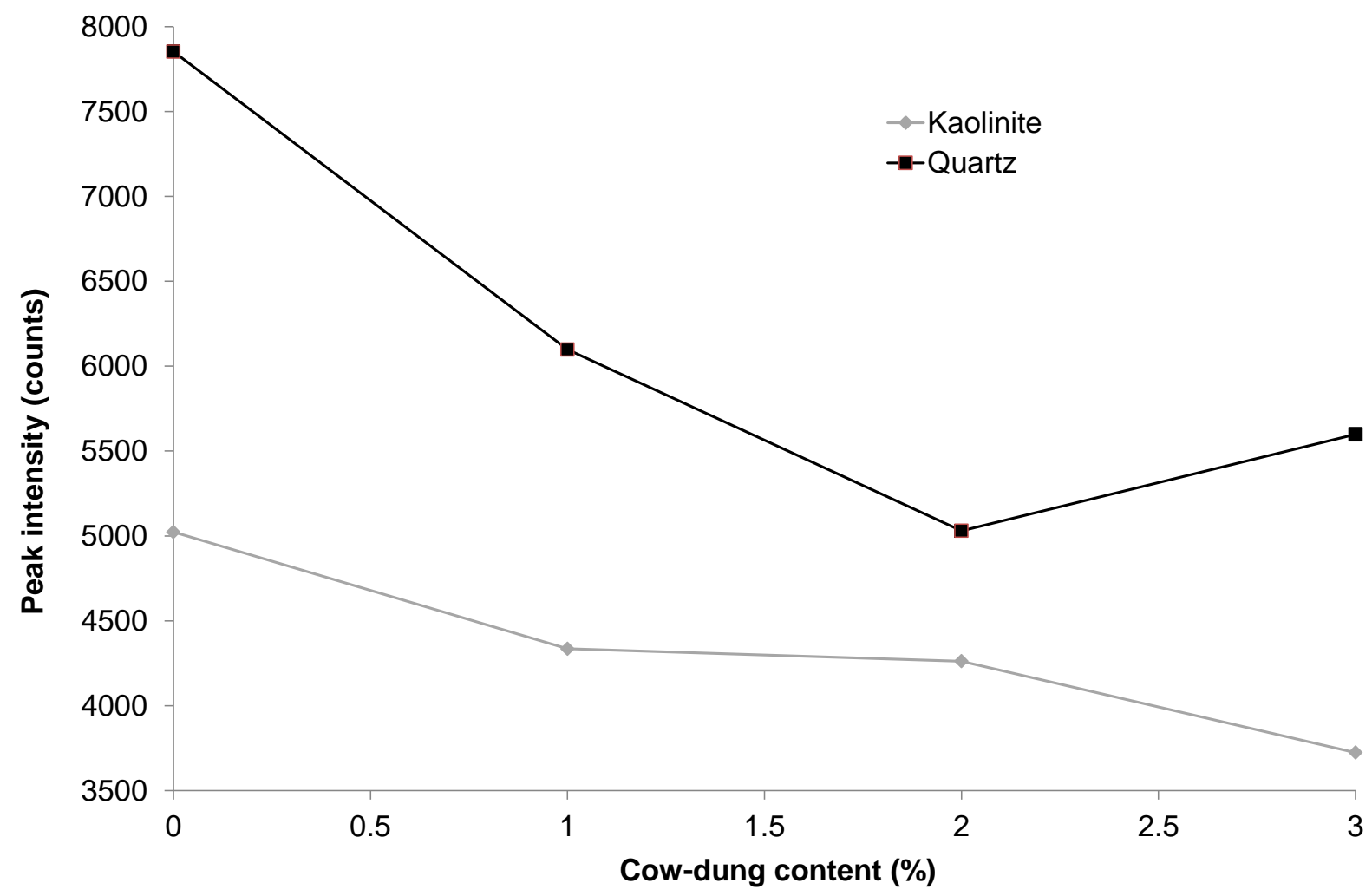

Fig. 11: Evolution of the intensity of prominent peaks of kaolinite and quartz with cow-dung additions

Fig. 11 clearly shows the diminution of these prominent peak intensities with cow-dung addition and proves that kaolinite and soluble quartz in a basic medium (fine quartz), react with cow-dung. An optimum is observed for quartz (around 3 wt.\%), probably linked to the amount of fine quartz. The explanation of this result is developed in the next section.

In fact, in aqueous solution, amine organic compounds $\left(\mathrm{RNH}_{2}\right.$ with $\mathrm{R}$ as an organic radical) contained in cow-dung produce a cationic compound by the following reaction:

$$
\mathrm{RNH}_{2}+\mathrm{H}_{2} \mathrm{O} \rightleftarrows \mathrm{RNH}_{3}{ }^{+}+\mathrm{OH}^{-}
$$

The measurement of $\mathrm{pH}$ of cow-dung was realized with the dilution of cow-dung in distilled water in the ratio in mass : 1/5 (cow-dung powder/ distilled water). As the cow-dung fermentation product is basic $(\mathrm{pH}=12)$, solubilization of the fine quartz and silica of kaolinite occurs, producing $\mathrm{SiO}_{4}{ }_{4}^{4-}$. $\mathrm{RNH}_{3}{ }^{+}$then reacts with $\mathrm{SiO}_{4}{ }^{4-}$ to produce $\mathrm{SiO}_{4}\left(\mathrm{NH}_{3}\right)_{4}$ which is an insoluble silicate amine according to the following reaction :

$$
4 \mathrm{RNH}_{3}{ }^{+}+\mathrm{SiO}_{4}{ }^{4-} \rightarrow \mathrm{SiO}_{4}\left(\mathrm{NH}_{3}\right)_{4}
$$

The latter compound is probably amorphous and/or present in small amounts $(<2 \mathrm{wt} . \%)$, which could be the reason why it is not detected by X-ray diffraction. This insoluble compound glues isolated soil particles together. The formation of this compound could constitute proof that kaolinite and quartz react with cow-dung.

\subsection{Physical and mechanical properties of adobes}

Freshly fractured pieces of adobes were examined by scanning electron microscopy (SEM) to highlight the effects of cow-dung additions on their physical and mechanical behaviour. The SEM micrographs of the natural adobes (a) and those amended with 3\% cow-dung (b) are presented in Fig. 12. SEM examination performed on the cow-dung-free sample shows a heterogeneous structure consisting of isolated particles with clearly visible pores dispersed in 
the adobe. With the addition of cow-dung, the isolated particles observed in cow-dung-free samples were connected, resulting in a more homogeneous microstructure with denser material at many parts, having fewer pores.
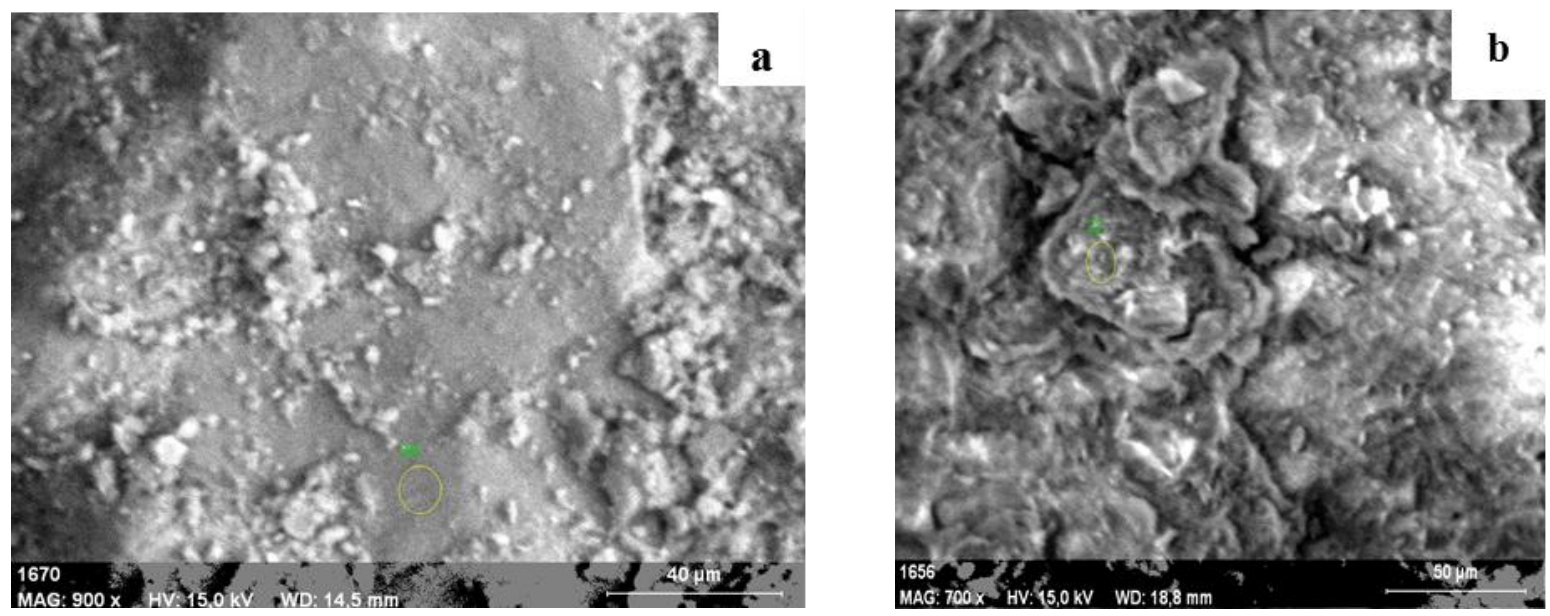

Fig. 12: Scanning electron microscopy images of the raw and cow-dung-amended adobes (a: raw material; b: 3wt.\% cow-dung)

The evolutions of water absorption and linear shrinkage versus cow-dung contents are plotted in Fig.13. The standard deviations on the measurements for water absorption and linear shrinkage are respectively around $0.30 \%$ and $0.33 \%$.

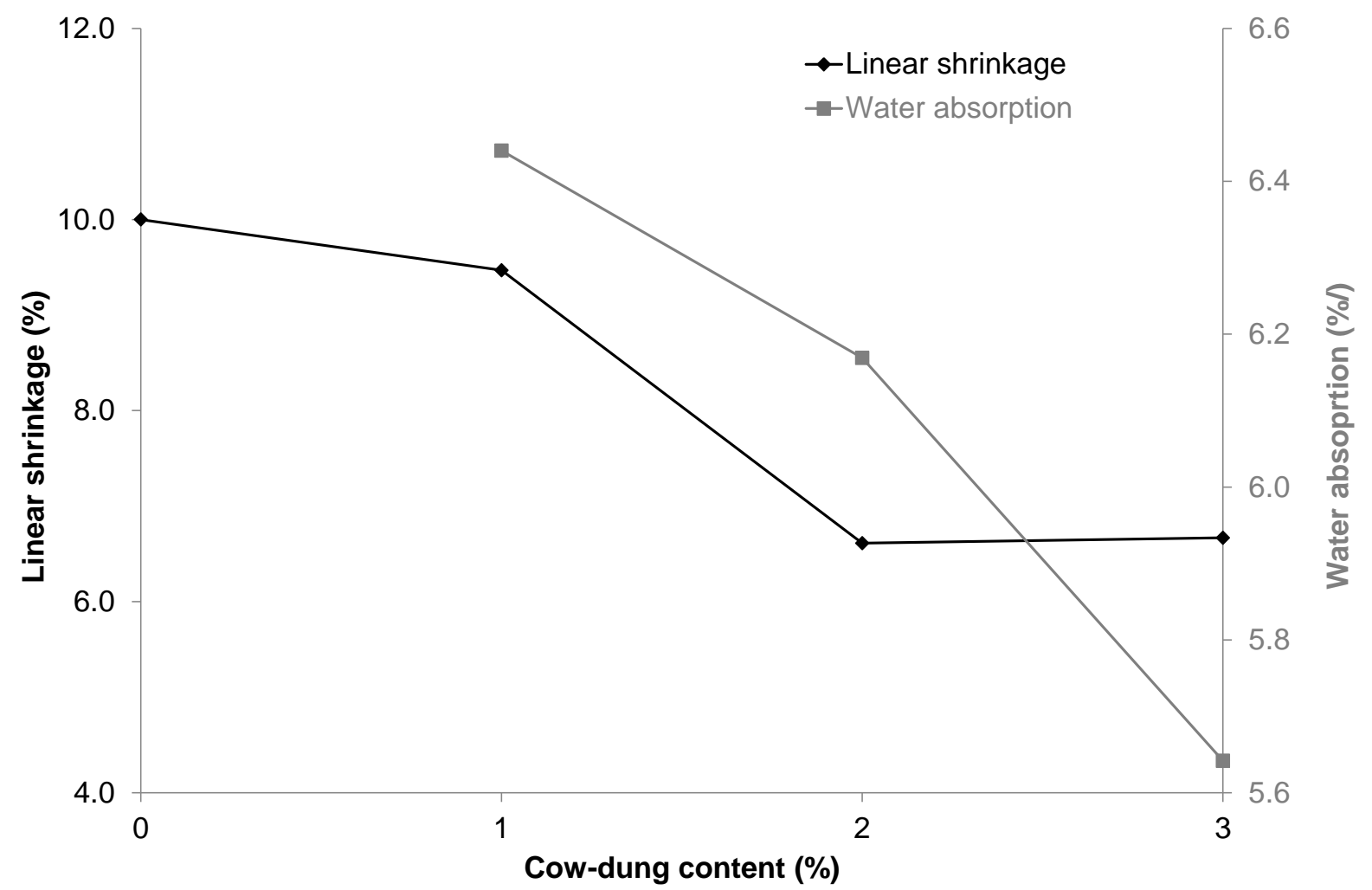

Fig. 13: Evolution of water absorption and linear shrinkage of adobes versus cow-dung contents

These two curves show the same trend: both properties decrease with cow-dung additions. Concerning water absorption, the adobes without cow-dung were destroyed when they were 
immersed in water, whereas those amended with cow-dung resisted. The presence of cowdung in clay mix improves the resistance of adobes to water because of the formation of insoluble silicate amine which glues isolated soil particles together. The material thus becomes less porous, according to SEM studies of adobes, and resistant to water. In consequence, the presence of cow-dung in the clay mix drastically reduces the water sensitivity of adobes and the harmful impact of water on their mechanical behaviour. For this reason, cow-dung is traditionally used in West Africa, particularly in Burkina Faso, as plaster for building materials.

The flexural and compressive strengths of adobes versus cow-dung content are presented in Fig. 14. The standards deviations of flexural and compressive strengths were around $0.04 \mathrm{MPa}$ and $0.28 \mathrm{MPa}$ respectively.

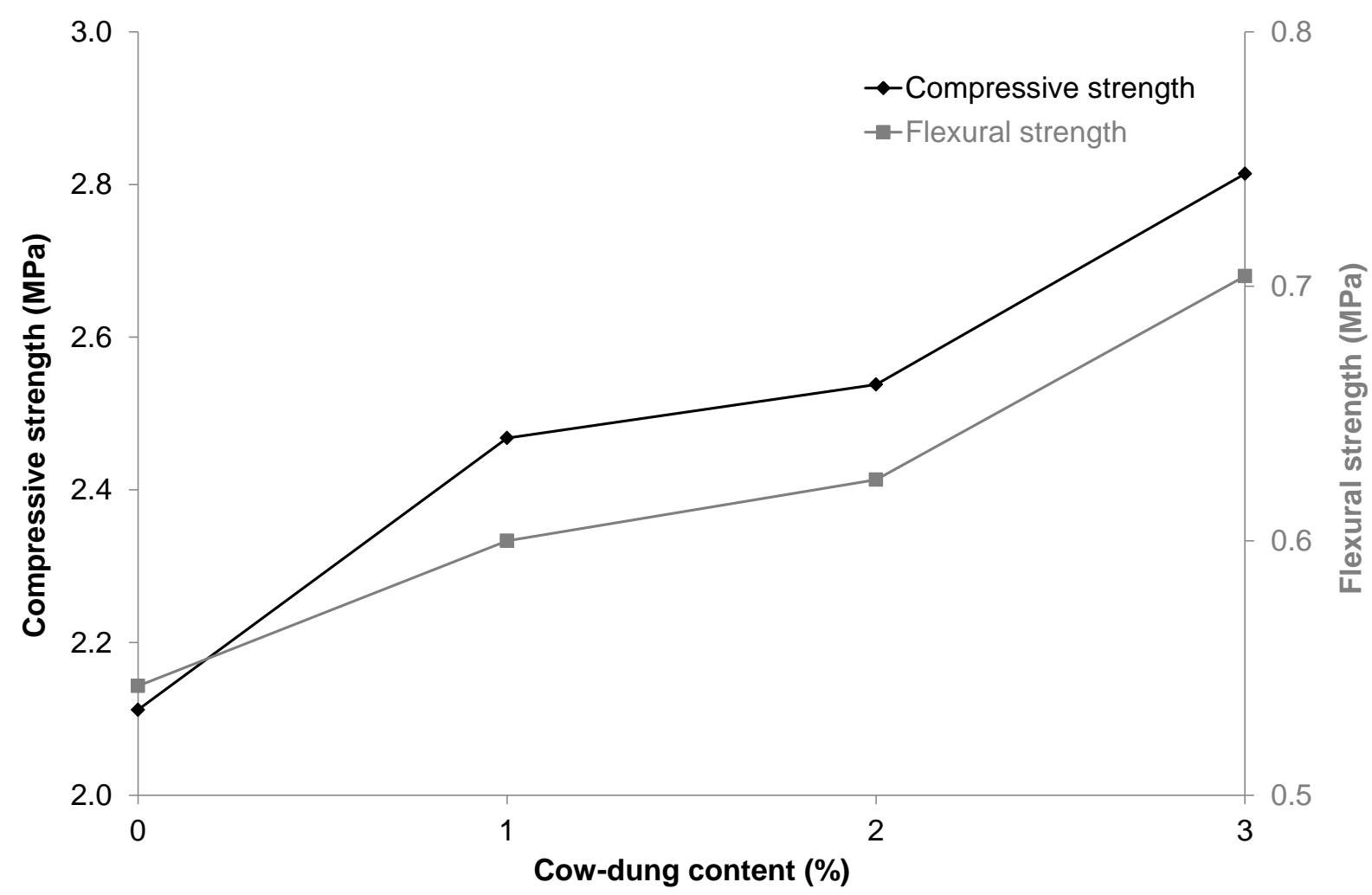

Fig. 14: Evolution of flexural and compressive strength of adobes versus cow-dung contents

These curves show the same trends. The mechanical parameters investigated increase with cow-dung additions due to the reduction of porosity and the non-propagation of cracks in adobes.

Fig. 15 correlates flexural and compressive strengths with water absorption. The distribution of points in the two graphs for each of the two cases shows that there is a strong correlation between compressive (or flexural) strength and water absorption. 


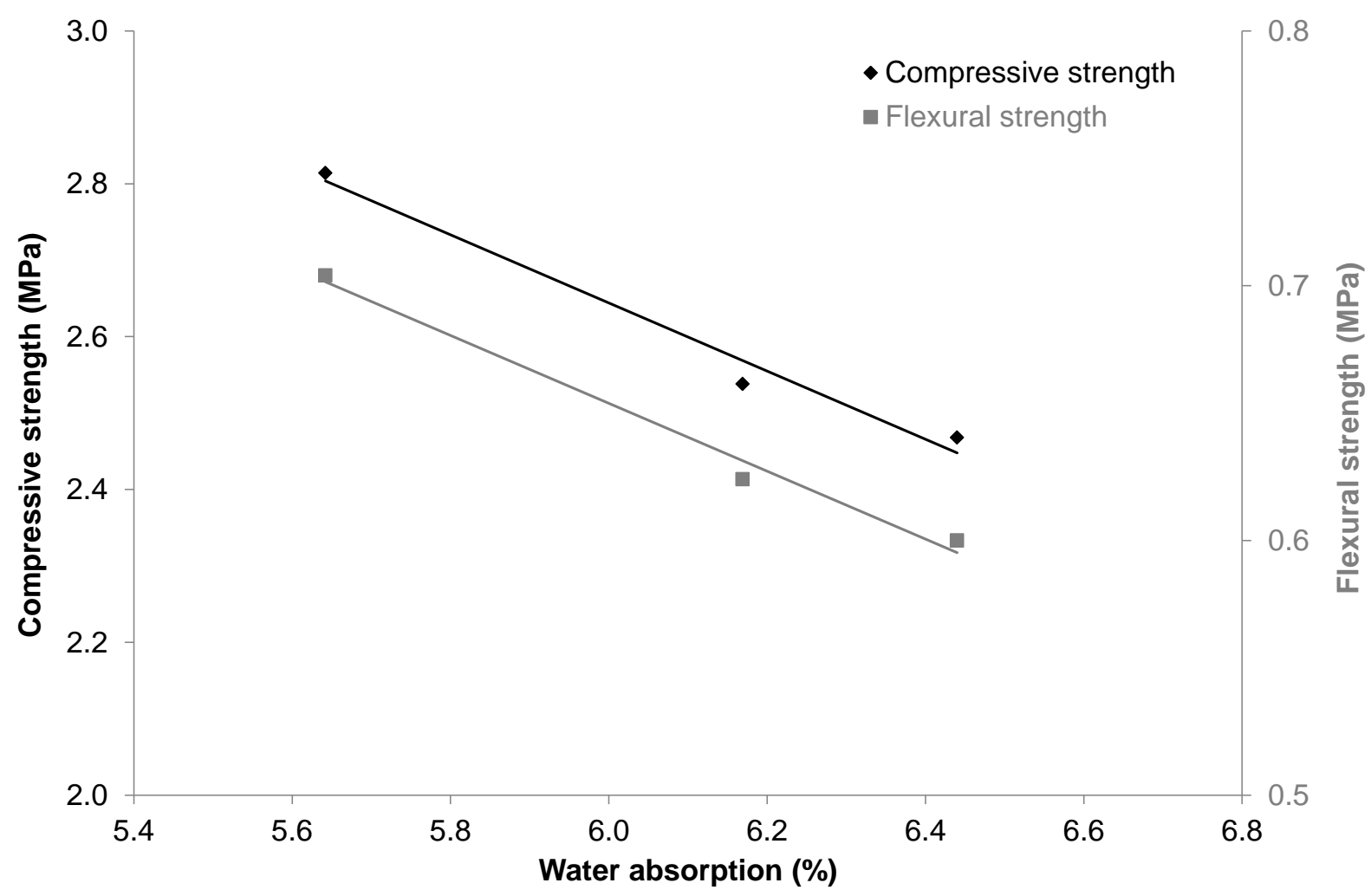

Fig. 15: Correlation curves between water absorption and compressive (or flexural) strength of adobes

With addition of cow-dung, an improvement in the mechanical properties of the specimens can be noted. This improvement is essentially due to the diminution of specimen porosity with cow-dung additions. In fact, during cow-dung fermentation by microbial action in the maceration step, microbial debris (organic matter) and amine organic compounds are produced. These microbial debris glue isolated soil particles, and therefore the specimens, together. Moreover, non-digested fibres lead to good adherence with the clay matrix because of their rough surface. Also, their presence in adobes prevents the propagation of cracks. Finally, the insoluble silicate amine formed glues the isolated soil particles together. The consequence is a reduction of the number and size of pores and an improvement in compressive strength.

The improvement of flexural strength with cow-dung additions could also be explained by the contribution of short fibres contained in the cow-dung. In fact, fibres are rich in cellulose which is known for its good tensile strength (300-500 MPa).

The compressive strengths measured during this study were higher than those reported by Vilane (2010). These differences could be linked to the difference of soils used in the two studies, especially considering their clay content (the amount of clay contained in the soil used by Vilane (10 wt.\%) was lower than in the sample studied here (36 wt.\%)). The presence of a large clay fraction is necessary to produce the insoluble silicate amine that glues the particles together, reducing the adobe porosity.

It would be interesting to compare the compressive strength obtained during the stabilization with cow-dung to that of adobes stabilized with kenaf (Hibiscus cannabinus fibres), another natural stabilizer used in Burkina Faso. The compressive strengths of the adobes amended with cow-dung present similar values to those measured on Pressed Adobe Blocks (PABs) stabilized by short fibres $(3 \mathrm{~cm}$ ) of Hibiscus cannabinus (Millogo et al. 2014) but the values 
obtained with cow-dung stabilization are better than those for PABs stabilized by long fibres $(6 \mathrm{~cm})$. The similarity of the results is linked to the length of fibres (fibres contained in cowdung are short) because the two soils used for these adobes had the same overall grain size distribution and the same mineralogical composition.

From another point of view, the flexural and compressive strengths of adobes studied in this paper were lower than those obtained with adobes manufactured with termite mound material, which has slight similarities with the mixtures stabilized with cow-dung (Millogo et al. 2011). In fact, termite mound material is composed of clay minerals and sand mixed with short fibres and the cohesion of isolated particles is ensured by organic polymers secreted by the termites during construction of the termite mound.

Generally, the mechanical properties of adobes stabilized with chemical binders, such as cement and lime, are better than those stabilized by cow-dung but the latter have the advantage of improving the resistance to water (Ngowi 1997; Vilane 2010; Millogo et al. 2008; Millogo et al. 2012). The magnitudes of flexural and compressive strengths are in the range of the values suggested by the standards related to adobes (Mbumbia et al. 2000). So manufactured adobes could be used without damage as building construction materials with an advantage linked to their low water absorption. This last property is very important for developing countries because expensive wall coating could be avoided if stabilized adobes stabilised were valorized as building material.

\section{Conclusions}

The effects of cow-dung on the microstructure, and physical and mechanical properties of adobes manufactured from a lateritic clay sample from Burkina Faso were investigated in this work. The mineralogical characterization of the soil used for the manufacture of adobes showed that it was mainly composed of kaolinite (66wt.\%), quartz (21wt.\%) and goethite (18wt.\%). In parallel, the characterization of the cow-dung used in this study showed that it contained short non-digested fibres and these fibres were composed of cellulose, hemicellulose and lignin. XRD studies on the soil amended by cow-dung showed that cowdung reacts with kaolinite and fine quartz, producing insoluble silicate amine, which glues the isolated particles together. The consequence of this is a transformation of the microstructure of adobes, which become more homogeneous with fewer pores.

The characterization of the adobes showed that cow-dung additions improved their physical and mechanical properties. This was due to the reaction of cow-dung with the soil highlighted during the microstructure study. One of the major effects of cow-dung additions is the significant improvement in the water resistance of adobe that permits us to conclude that the manufactured adobes are suitable as building materials in wet climates.

The present work does not give the optimum amount of cow-dung that should be mixed into clay material in order to obtain the best physical and mechanical properties. Neither does it investigate the characterization of newly formed compounds such as silicate amine. These aspects will be the subject of future research. Also, given that the adobes could be used in building construction, thermal and hygrothermal studies of these adobes could be very important. The plant fibres may greatly modify the hygrothermal behaviour of the adobes due to their high ability to absorb water.

Finally, the interest of such work for the design of future eco-materials could be to use the lessons of the past coming from the cultural heritage (stabilization of adobes using cow-dung) to develop new, eco-efficient chemical binders based on the same type of chemical reactions 
with clayey soil. These new binders could advantageously replace the use of conventional cow-dung and thus lead to better acceptance by the people who would use these stabilized adobes.

\section{Acknowledgements}

Younoussa Millogo would like to acknowledge the financial support of Université Paul Sabatier of Toulouse, France for welcoming him as a Visiting Professor in the laboratory "Matériaux et Durabilité des Constructions". This work was co-founded by the Rhône-Alpes Regional Council through the CMIRA Fellowship granted to JC Morel.

\section{References}

Aubert JE, Fabbri A, Morel JC, Maillard P (2013) A soil block with a compressive strength higher than $45 \mathrm{MPa}$ ! Constr Build Mater 47:366-9.

Aubert JE, Maillard P, Morel JC, Alrafii M (2015) Towards a simple compressive strength test for earth bricks? Mater Struct DOI 10.1617/s11527-015-0601-y.

Danso H, Martinson B, Ali M, Mant C (2015) Performance characteristics of enhanced soil blocks: a quantitative review. Build Res Inf 43:253-62.

El-Shekeil YA, Sapuan SM, Abdan K, Zainudin ES (2012) Influence of fibre content on the mechanical and thermal properties of Kenaf fibre reinforced thermoplastic polyurethane composites. Mater Design 40:299-303.

Ghavami K, Toledo Filho RD, Barbosa NP (1999) Behaviour of composite soil reinforced with natural fibres. Cem Concr Compos 21:39-48.

Mbumbia L, Mertens de Wilmars A, Tirlocq J, Vandeneede V (2000) Influence du processus de fabrication sur les propriétés des briques à base de latérite. Sil Ind 65:101-9.

Mesbah A, Morel JC, Walker P, Ghavami K (2004) Development of a direct tensile test for compacted soil blocks reinforced with natural fibres. J Mater Civil Eng 16:95-8.

Minke G (2006) Building with earth. Birkhäuser - Publishers for Architecture, Basel, Switzerland.

Millogo Y, Hajjaji M, Ouedraogo R (2008) Microstructure and physical properties of limeclayey adobe bricks. Constr Build Mater 22:2386-92.

Millogo Y, Hajjaji M, Morel JC (2011) Physical properties, microstructure and mineralogy of termite mound material considered as construction materials. Appl Clay Sci 52:160-4.

Millogo Y, Morel JC (2012) Microstructural characterization and mechanical properties of cement stabilised adobes. Mater Struct 45:1311-8.

Millogo Y, Morel JC, Aubert JE, Ghavami K (2014) Experimental analysis of pressed adobe blocks reinforced with Hibiscus cannabinus fibres. Constr Build Mater 52:71-8.

Millogo Y, Aubert JE, Hamard E, Morel JC (2015) Properties of Kenaf fibres from Burkina Faso used as reinforcement of earth blocks. Materials 8:2332-45.

Morān J I, Alvarez V A, Cyras V P, Vāsquez A (2008) Extraction of cellulose and preparation of nanocellulose. Cellulose 15:149-59. 
Morel JC, Aubert JE, Millogo Y, Hamard E, Fabbri A (2013) Some observations about the paper "Earth construction: Lessons from the past for future eco-efficient construction" by F. Pacheco-Torgal and S. Jalali. Constr Build Mater 44:419-21.

Ngowi AB (1997) Improving the traditional earth construction: a case study of Botswana. Constr Build Mater 11:1-7.

Pacheco-Torgal F, Jalali S (2012) Earth construction: lessons from the past for future ecoefficient construction. Constr Build Mater 29:512-9.

Vilane BRT (2010) Assessment of stabilization of adobes by confined compression tests. Biosyst Eng 106:551-8. 